\begin{tabular}{|l|l|l|}
\hline \multicolumn{2}{|c|}{ PublisherInfo } \\
\hline \hline PublisherName & $:$ & BioMed Central \\
\hline \hline PublisherLocation & $:$ & London \\
\hline \hline PublisherImprintName & $:$ & BioMed Central \\
\hline \hline
\end{tabular}

\title{
Pulmonary vascular effects of isoflurane
}

\begin{tabular}{|l|l|l||}
\hline \multicolumn{2}{|c|}{ ArticleInfo } \\
\hline \hline ArticleID & $:$ & 4120 \\
\hline \hline ArticleDOI & $:$ & $10.1186 /$ ccf-1999-501 \\
\hline \hline ArticleCitationID & $:$ & 501 \\
\hline \hline ArticleSequenceNumber & $:$ & 57 \\
\hline \hline ArticleCategory & $:$ & Paper Report \\
\hline ArticleFirstPage & $:$ & 1 \\
\hline \hline ArticleLastPage & $:$ & 4 \\
\hline \hline & & RegistrationDate : 1999-6-15 \\
\hline ArticleHistory & $:$ & OnlineDate \\
\hline \hline ArticleCopyright & $:$ & Current Science Ltd1999-6-15 \\
\hline \hline ArticleGrants & $:$ & \\
\hline \hline ArticleContext & $:$ & 130541111 \\
\hline \hline
\end{tabular}




\section{Keywords}

Lungs, preconstriction, vasoregulation

\section{Comments}

This study provides a lot of information about the pulmonary vascular response to systemic hypotension and the effects of isoflurane and other drugs that have an effect on the $\mathrm{K}+\mathrm{ATP}$ channel. The method is interesting in that, by using chronically instrumented dogs living normally with lines implanted for several weeks, many possible confounding factors relating to surgery are avoided. Even with this carefully applied method the individual effects of drugs were still probably modified by the homeostatic effects of systemic hypotension. Additionally there is contradictory evidence about how isoflurane interacts with the $\mathrm{K}+\mathrm{ATP}$ channel. There is also interaction between beta adrenoceptors, adenosine receptors and the $\mathrm{K}+\mathrm{ATP}$ channel. The findings of this study provide level III evidence of attenuation of the $\mathrm{K}+$ ATPmediated pulmonary vasodilation and the vasoconstrictor response to hypotension. The results do not enable any clear conclusion to be drawn about the nature of isofluranes action in this respect. It is an interesting paper worth reading for the experimental methods.

\section{Introduction}

Isoflurane has recently been investigated for its effects on $\mathrm{K}+\mathrm{ATP}$ channels. The anesthetic agent seems to exert dilator and constrictor effects on pulmonary vasculature. It attenuates the reponse of hypoxic pulmonary vasoconstriction (HPV) yet has no effect on the vasoconstrictor response to alphaadrenoceptor agonists. It potentiates cyclic adenosine monophosphate (c amp) mediated vasodilatation yet attenuates the dilator response to endothelium related cyclic guanosine monophosphate related agonists. $\mathrm{K}+$ ATP channels mediate another major mechanism of pulmonary vasodilatation. Activation causes membrane hyperpolarization and vasodilation via reduced calcium influx. Activation by agonists such as lemakalim causes profound pulmonary vasodilation which is blocked by antagonists such as glibenclamide. In this study chronically instrumented dogs were used as the model to assess changes in pulmonary vascular response.

\section{Aims}


(1) To assess the effect of isoflurane on the pulmonary vasodilator response to the $\mathrm{K}+\mathrm{ATP}$ channel agonist lemakalim.

(2) To determine whether inhibition of $\mathrm{K}+\mathrm{ATP}$ channels with glibenclamide would inhibit the pulmonary vasoconstrictor response to hypotension in the concious state.

(3) To determine whether the pulmonary vasoconstrictor response to hypotension is altered by isoflurane anesthesia.

\section{Methods}

Preparation of animals: Fifteen mongrel dogs were anesthetized and catheters inserted into the descending thoracic aorta, left and right atrium and main pulmonary artery. Hydraulic occluders were positioned around the right main pulmonary artery and thoracic inferior vena cava. An electromagnetic flow probe was placed around the left main pulmonary artery. The dogs were given at least 2 weeks to recover prior to starting experimental protocols. During the course of the experiments, measurements were made of left pulmonary blood flow (LQ; via the electromagnetic flow probe), systemic arterial and mixed venous blood gases and $\mathrm{pH}$, and oxyhemoglobin saturation.

Five different experimental protocols were applied with the dogs lying on their right sides. The 'concious' dogs were not sedated. Left pulmonary vascular pressure flow (LPQ) plots were used to assess the effects of various protocols. These plots were generated from pulmonary arterial pressure (PAP), left atrial pressure (LAP) and LQ, with the occluder inflated around the right main pulmonary artery.

\section{Results}

(1) Isoflurane had no effect on baseline pulmonary circulation. In the preconstricted pulmonary circulation, lemokalim induced pulmonary vasodilation which was significantly attenuated in the isoflurane-anesthetised state compared with the conscious state.

(2) Circulatory hypotension, induced by occlusion of the inferior vena cava, resulted in an increase in pulmonary vasoconstriction. Isoflurane-anesthetised dogs showed a decrease in the magnitude of hypotension-induced increases in PAP-LAP compared to intact and conscious dogs.

(3) In both isoflurane-anesthetised and conscious models, glibenclamide potentiated the pulmonary vasoconstrictor response to circulatory hypotension. 


\section{Discussion}

Isoflurane anesthesia attenuates the pulmonary vasodilator response to exogenous $\mathrm{K}+\mathrm{ATP}$ channel activation and the pulmonary vasoconstrictor response to circulatory hypotension. The authors suggest that the activation of reflex vasoconstrictor mechanisms is unlikely to be causing the attenuating effect of isoflurane on lemakalim-induced pulmonary vasodilation. It is suggested that isoflurane may be affecting the endothelial nitric-oxide-prostacyclin interaction thus attenuating the endothelial-dependent relaxation. A direct effect of isoflurane on $\mathrm{K}{ }^{+} \mathrm{ATP}$ channels also appears unlikely as the $\mathrm{K}{ }^{+} \mathrm{ATP}$ channels were not tonically active in the pulmonary circulation. The physiological advantage of hypotensioninduced pulmonary vasoconstriction is considered. This paper investigated the previously unknown effect of anesthesia on the pulmonary vascular response to hypotension. Possible explanations for the mechanisms of attenuation of the pulmonary vasoconstrictor response include modification of reflex baroreceptor pathways or nervous system signal processing.

\section{References}

1. Fujiwara Y, Murray PA: Effects of isoflurane anesthesia on pulmonary vascular response to $\mathrm{K}+$ ATPchannel activation and circulatory hypotension in chronically instrumented dogs. Anesthesiology. 1999, 90: 799-811. 